\title{
BIRTH ORDER AND ANDROPHILIC MALE-TO-FEMALE TRANSSEXUALISM IN BRAZIL
}

DOUG P. VANDERLAAN $*{ }^{+1}$, RAY BLANCHARD $\$$, KENNETH J. ZUCKER $\ddagger$, RAFFAEL MASSUDA§, ANNA MARTHA VAITSES FONTANARI§, ANDRÉ OLIVEIRA BORBA§, ANGELO BRADELLI COSTA§, MAIKO ABEL SCHNEIDER $\S$, ANDRESSA MUELLER $\S$, BIANCA MACHADO BORBA SOLL§, KARINE SCHWARZ§, DHIORDAN CARDOSO DA SILVA§ AND MARIA INÊS RODRIGUES LOBATO§

*Department of Psychology, University of Toronto Mississauga, Mississauga, Ontario, Canada, $\dagger$ Child, Youth and Family Division, Underserved Populations Research Program, Centre for Addiction and Mental Health, Toronto, Ontario, Canada, $\ddagger$ Department of Psychiatry, University of Toronto, Toronto, Ontario, Canada and $\S$ Gender Identity Program-PROTIG, Hospital de Clinicas de Porto Alegre, Rio Grande do Sul, Porto Alegre, Brazil

Summary. Previous research has indicated that biological older brothers increase the odds of androphilia in males. This finding has been termed the fraternal birth order effect. The maternal immune hypothesis suggests that this effect reflects the progressive immunization of some mothers to male-specific antigens involved in fetal male brain masculinization. Exposure to these antigens, as a result of carrying earlier-born sons, is hypothesized to produce maternal immune responses towards later-born sons, thus leading to femaletypical neural development of brain regions underlying sexual orientation. Because this hypothesis posits mechanisms that have the potential to be active in any situation where a mother gestates repeated male fetuses, a key prediction is that the fraternal birth order effect should be observable in diverse populations. The present study assessed the association between sexual orientation and birth order in androphilic male-to-female transsexuals in Brazil, a previously unexamined population. Male-to-female transsexuals who reported attraction to males were recruited from a specialty gender identity service in southern Brazil $(n=118)$ and a comparison group of gynephilic non-transsexual men $(n=143)$ was recruited at the same hospital. Logistic regression showed that the transsexual group had significantly more older brothers and other siblings. These effects were independent of one

${ }^{1}$ Corresponding author. Email: doug.vanderlaan@utoronto.ca 
another and consistent with previous studies of birth order and male sexual orientation. The presence of the fraternal birth order effect in the present sample provides further evidence of the ubiquity of this effect and, therefore, lends support to the maternal immune hypothesis as an explanation of androphilic sexual orientation in some male-to-female transsexuals.

\section{Introduction}

Androphilia refers to sexual attraction and arousal towards adult males whereas gynephilia refers to sexual attraction and arousal towards adult females. Numerous studies have shown that older brothers increase the odds of androphilia in later-born males. The observed increase in odds is typically between 15 and 50\% per older brother (e.g. Blanchard \& Bogaert, 1996; Blanchard et al., 1998; Blanchard \& Lippa, 2007). This phenomenon has been termed the fraternal birth order effect. This effect is most easily demonstrated when the mean number of older brothers is elevated among androphilic, compared with gynephilic, males and the mean sum of other siblings (i.e. older sisters + younger brothers + younger sisters) is similar across these groups. If the mean sums of other siblings are not similar, or if there are other large demographic differences between groups, statistical corrections are sometimes needed to see the effect (e.g. Blanchard, 2014).

The best-developed explanation of the fraternal birth order effect is the maternal immune hypothesis (Blanchard \& Bogaert, 1996; Bogaert \& Skorska, 2011). This hypothesis argues that antigens from male fetuses' cells enter maternal circulation during pregnancy, promoting an immune response to these male-specific antigens. This immune response would, in turn, produce long-lasting effects on the brain of the male fetus, preventing its neurons from making a male-typical pattern of connections, resulting in attraction towards men rather than women. In its general form, the maternal immune hypothesis does not specify which male-specific proteins are most likely to be involved. Based on considerations like tissue distribution and prenatal expression, it has been conjectured (see Blanchard et al., 2002; Blanchard, 2004) that two likely proteins are PCDH11Y (Blanco et al., 2000) and NLGN4Y (Jamain et al., 2003). As noted by Blanchard (2008), the maternal immune hypothesis does not challenge the long-standing theory that sexual orientation is primarily influenced via prenatal sex hormone exposure; rather, it proposes that sexual orientation in the human male brain is influenced by two systems: one driven by prenatal sex hormones and a supplementary system driven by male-specific proteins under direct genetic control.

Several lines of research support the plausibility of the maternal immune hypothesis. To begin with, fetal cells and fetal molecular material have been found in maternal circulation during early pregnancy and postpartum, a phenomenon called microchimerism (Lo et al., 1996; O’Donoghue et al., 2004; Gammil et al., 2010). Further evidence points to a specific T-cell-mediated immune response towards antigens arisen from the Y-chromosome, called male antigens (HY) (Piper et al., 2007; Khan \& Baltimore, 2010; Lissauer et al., 2012; Dierselhuis et al., 2014) as well as polymorphisms to minor histocompatibility complexes (Christiansen et al., 2012), which might play a significant role in the maternal immune response to male fetuses. Additional evidence shows higher prevalence of male fetus miscarriages in women with a supposedly more HY-reactive 
HLA (Hiby et al., 2008; Nielsen et al., 2009), and the number of sons a woman has throughout life has been associated with age-linked inflammation (Marttila et al., 2015), thus providing further evidence of a male-specific maternal immune response.

In addition, the fraternal birth order effect does indeed appear to be prenatal in origin. First, relatively low birth weight provides a marker of prenatal exposure to a maternal immune response (for review, see VanderLaan et al., 2015) and androphilic males who have older brothers exhibit lower birth weights (Blanchard \& Ellis, 2001; Blanchard et al., 2002; VanderLaan et al., 2015). Hence, even at the time of birth, there seems to be a physical marker of sexual orientation (i.e. birth weight) that is related to the number of older brothers. Second, Bogaert (2006) examined the association between male sexual orientation and biological siblings (i.e. born from the same mother) and non-biological siblings (i.e. adoptive, step or paternal half-siblings). Whether and how long probands were reared with these siblings was also considered. Biological older brothers significantly predicted male sexual orientation regardless of whether or how long probands were reared with these brothers. In contrast, the remaining sibling categories, including non-biological older brothers, did not.

By virtue of suggesting that the fraternal birth order effect is prenatal in origin, the maternal immune hypothesis posits mechanisms that have the potential to operate in any situation where a mother gestates a male fetus in more than one pregnancy. As such, one would predict the fraternal birth order effect to be nearly ubiquitous - with the exception of populations where people do not have older brothers (e.g. China: Xu \& Zheng, 2015). One approach for establishing the ubiquity of this effect has been to examine a variety of sample types. To date, the fraternal birth order effect has been documented in university and community convenience samples, national probability samples, clinical samples of male-to-female transsexuals, clinical samples of men who are primarily attracted to prepubescent or pubescent children, clinical samples of natal male children and adolescents who are likely to be androphilic as adults, and archival samples of men interviewed decades ago (for reviews, see Blanchard, 1997, 2004; Bogaert \& Skorska, 2011; VanderLaan et al., 2014; Blanchard \& VanderLaan, 2015). In addition, this effect has been documented in several countries (e.g. Canada: Blanchard \& Bogaert, 1996; Italy: Camperio Ciani et al., 2004; The Netherlands: Schagen et al., 2012; Samoa: VanderLaan \& Vasey, 2011; Spain: Gómez-Gil et al., 2011; Turkey: Bozkurt et al., 2015; UK: King et al., 2005; USA: Schwartz et al., 2010).

Despite the consistency with which the fraternal birth order effect has been observed, there has been debate regarding its ubiquity and, by extension, the role of maternal immune factors in the development of male sexual orientation. Some studies failed to replicate this effect, raising scepticism about its importance (e.g. Currin et al., 2015; Frisch \& Hviid, 2006; Kashida \& Rahman, 2015). Other research reported that androphilic males show elevations in older brothers and older sisters, raising the question of whether the male sexual orientation difference in birth order is specific to older brothers (e.g. King et al., 2005).

Blanchard and VanderLaan (2015) addressed both of these challenges. First, their reanalyses of the data presented by Frisch and Hviid (2006) and Kashida and Rahman (2015), respectively, indicated that the fraternal birth effect was, in fact, evident in these samples. Further, they noted that failures to replicate (Type II error) are to be expected in some proportion of studies, as is the case with any true effect. Second, they explained 
that number of older brothers tends to be correlated positively with number of older sisters. Thus, although one would expect to observe older sister effects in some proportion of samples, older sister effects should not be observed as consistently as older brother effects. Indeed, Blanchard and VanderLaan (2015) presented a meta-analysis showing that only the older brother effect was reliably associated with male sexual orientation across previously published studies.

An additional means of continuing to evaluate the reliability and ubiquity of the fraternal birth order effect is to examine birth order in relation to male sexual orientation in previously unexamined populations. The present study did so by comparing numbers of older brothers and numbers of other siblings in a sample of Brazilian male-to-female transsexuals who are attracted to men vs a comparison group of non-transsexual gynephilic men.

\section{Methods}

\section{Participants}

Participants $(N=261)$ were recruited at the Hospital de Clínicas de Porto Alegre (HCPA) from 2008 to 2013. All male-to-female transsexual participants $(n=118)$ were at least 18 years of age and were patients of the Gender Identity Program (PROTIG) who met the DSM-IV-TR criteria for Gender Identity Disorder (GID; American Psychiatric Association, 2000). Prior to assessment by PROTIG, all had previously used hormonal medications without medical guidance, but none had undergone sexreassignment surgery. Three individuals assessed by PROTIG were excluded from the present study because they evidenced psychotic symptoms that limited the ability to make an accurate diagnosis concerning GID. None had a disorder of sex development.

The comparison group of gynephilic men $(n=143)$ consisted of medication-free volunteers who had no current, past history, or first-degree family history of a major psychiatric disorder, dementia or mental retardation. The sample was collected from non-psychiatric medical patients and companions at the outpatient clinics at HCPA, aged 18 years old or greater.

\section{Measures}

Male-to-female transsexuals and men completed a questionnaire about their age, year of birth and numbers of biological older and younger brothers and sisters from the same biological mother. Information regarding the sexual orientation of transsexual patients was obtained during semi-structured interviews with a psychiatrist (patients attended group and/or individual medical appointments on a biweekly basis). On the basis of this clinical information, all transsexuals were categorized as sexually attracted

towards men. For the comparison group of men, they were asked to self-report their sexual orientation identity. All men self-reported a heterosexual sexual orientation identity (i.e. gynephilia, sexual attraction towards women).

\section{Ethics statement}

This research was approved by the institutional research ethics review board at the Hospital de Clínicas de Porto Alegre (HCPA). 


\section{Results}

Table 1 shows descriptive statistics regarding age, year of birth and numbers of older brothers and other siblings by group. Male-to-female transsexuals were significantly younger (Levene's test for equality of variances: $F=35.53, p<0.001$, two-tailed independent samples $t$-test, $t(231.71)=-5.48, p<0.001)$ and had significantly later years of birth (Levene's test for equality of variances: $F=39.18, p<0.001$, two-tailed independent samples $t$-test, $t(227.64)=3.54, p<0.001)$. The correlation between age and year of birth was near perfect (two-tailed Pearson's $r=-0.99, p<0.001$ ), indicating that these variables were redundant with respect to the information they provided. As such, only age was retained as a control variable when comparing groups on sibship composition.

Table 2 summarizes the results of a logistic regression examining group differences in sibship composition. Group membership was the criterion variable with the male-tofemale transsexuals coded as 1 and the control men coded as 0 . Predictors in the model included: age, number of older brothers, number of other siblings, the interaction between age and number of older brothers, and the interaction between age and number of other siblings. All predictors were first centred to reduce multicollinearity and then entered in the model simultaneously to identify the unique contribution of each variable to predicting group membership (i.e. male-to-female transsexuals vs men). Male-tofemale transsexuals had significantly more older brothers and significantly more other siblings. In addition, there was a significant interaction between age and number of other siblings such that probands in the present sample who were younger and had larger numbers of other siblings were more likely to be male-to-female transsexuals.

Table 1. Descriptive statistics

\begin{tabular}{|c|c|c|c|c|}
\hline & \multicolumn{2}{|c|}{$\begin{array}{l}\text { Male-to-female transsexuals } \\
\qquad(n=118)\end{array}$} & \multicolumn{2}{|c|}{$\begin{array}{l}\text { Gynephilic men } \\
\quad(n=143)\end{array}$} \\
\hline & Mean & SD & Mean & SD \\
\hline Age & 30.14 & 8.28 & 38.02 & 14.58 \\
\hline Year of birth & 1980.02 & 7.99 & 1974.98 & 14.58 \\
\hline Number of older brothers & 0.92 & 1.21 & 0.74 & 0.99 \\
\hline Number of other siblings ${ }^{\mathrm{a}}$ & 2.18 & 1.80 & 1.98 & 1.79 \\
\hline
\end{tabular}

${ }^{\mathrm{a}}$ Number of older sisters + younger brothers + younger sisters.

Table 2. Logistic regression predicting group membership

\begin{tabular}{|c|c|c|c|c|c|}
\hline Predictor & $B$ & SE & Wald's $\chi^{2}(d f=1)$ & $p$-value & Odds ratio \\
\hline Age & -0.073 & 0.014 & 26.02 & $<0.001$ & 0.93 \\
\hline Number of older brothers & 0.277 & 0.126 & 4.86 & 0.028 & 1.32 \\
\hline Number of other siblings ${ }^{\mathrm{a}}$ & 0.221 & 0.091 & 5.94 & 0.015 & 1.25 \\
\hline Age $\times$ number of older brothers & 0.018 & 0.013 & 1.99 & 0.158 & 1.02 \\
\hline Age $\times$ number of other siblings & -0.022 & 0.009 & 6.26 & 0.012 & 0.98 \\
\hline
\end{tabular}

Group is the criterion variable with men coded as 0 and male-to-female transsexuals coded as 1 .

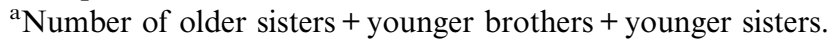




\section{Discussion}

The present study examined the fraternal birth order effect in Brazil, a previously unexamined population. Consistent with the maternal immune hypothesis and numerous previous studies conducted in other populations, Brazilian male-to-female transsexuals who reported sexual attraction towards men had significantly greater numbers of older brothers than a comparison group of gynephilic non-transsexual men. Importantly, this effect was independent of numbers of other siblings, thus providing further evidence of the unique contribution of older brothers to the development of same-sex sexual orientation among males.

In addition to documenting the fraternal birth order effect in the present sample, the odds ratio associated with this effect is noteworthy. Each additional older brother increased the odds of being in the male-to-female transsexual group by $32 \%$ (see Table 2 ). This value falls in the middle of the range of 15-50\% reported previously (Blanchard \& Bogaert, 1996; Blanchard et al., 1998; Blanchard \& Lippa, 2007) and is remarkably similar to the values of $33 \%$ reported for a Canadian sample (Cantor et al., 2002) and 34\% reported for a Samoan sample (VanderLaan \& Vasey, 2011). Thus, across diverse populations, the fraternal birth order effect has been documented and each additional older brother contributes similarly to the odds of developing an androphilic sexual orientation in natal males. These patterns are consistent with the maternal immune hypothesis and suggest that the influence of older brothers on male sexual orientation development is ubiquitous.

It is less clear, however, whether older brothers, via maternal immune mechanisms, have a more general influence on male psychosexual development that includes the domains of gender behaviour and identity in addition to sexual orientation. Gay men tend to exhibit elevated cross-gender behaviour and identity during childhood (Bailey \& Zucker, 1995; Rieger et al., 2008) and report some female-typical characteristics during adulthood (for review, see Lippa, 2005). Also, as was the case with the present study, many studies documenting the fraternal birth order effect examined samples of natal males who exhibited marked cross-gender behaviour and identity (for review, see VanderLaan et al., 2014). As such, some have suggested that fraternal birth order may not only relate to sexual orientation, but also to female-typical gender expression and identity, among androphilic natal males (Wampold, 2013; VanderLaan et al., 2015).

To date, data bearing on this issue are limited. Two studies did not find associations between numbers of older brothers and female-typical characteristics among gay men (Bogaert, 2003; Rahman, 2005; although see VanderLaan et al., 2015, for recent insights into why these studies may have not found such an effect). In four other studies, there was no fraternal birth order effect among clinical samples of natal males who exhibited marked cross-gender behaviour and identity but did not report predominant sexual attraction towards males (Blanchard \& Sheridan, 1992; Blanchard et al., 1996; Green, 2000; VanderLaan et al., 2014). Thus, although further data are needed to address this issue, it appears that if the fraternal birth order effect and maternal immune hypothesis apply to variation in natal male gender expression as well as sexual orientation, then they probably only apply to natal males who exhibit both cross-gender characteristics and androphilic sexual orientation.

Apart from an older brother effect, two additional effects were observed in the present study. First, male-to-female transsexuals had greater numbers of siblings other 
than older brothers. It is important to note that this effect was independent of the older brother effect discussed above. Furthermore, it is not uncommon for other sibling category effects to be observed in studies of birth order and male sexual orientation, although they are observed with less regularity than older brother effects (for review, see Blanchard \& VanderLaan, 2015). As such, the presence of the other sibling effect in the present sample (Table 2) is not inconsistent with research on this topic, the fraternal birth order effect or the maternal immune hypothesis. Second, there was an interaction between age and number of other siblings in the prediction of group such that the transsexual probands were more likely to be younger and to have more other siblings. Such a finding has not been reported in the literature previously and there is no a priori reason to expect such a pattern. Unless this pattern is replicated in future studies, the most reasonable explanation is that this interaction effect was due to some form of sampling bias and is, therefore, unlikely to be theoretically meaningful.

\section{Acknowledgments}

DPV was supported by a Canadian Institutes of Health Research Postdoctoral Fellowship and by the University of Toronto Mississauga.

\section{References}

American Psychiatric Association (2000) Diagnostic and Statistical Manual of Mental Disorders, 4th edition. American Psychiatric Association, Washington, DC.

Bailey, J. M. \& Zucker, K. J. (1995) Childhood sex-typed behavior and sexual orientation: a conceptual analysis and quantitative review. Developmental Psychology 31, 43-55.

Blanchard, R. (1997) Birth order and sibling sex ratio in homosexual versus heterosexual males and females. Annual Review of Sex Research 8, 27-67.

Blanchard, R. (2004) Quantitative and theoretical analyses of the relation between older brothers and homosexuality in men. Journal of Theoretical Biology 230, 173-187.

Blanchard, R. (2008) Review and theory of handedness, birth order, and homosexuality in men. Laterality: Asymmetries of Body, Brain and Cognition 13, 51-70.

Blanchard, R. (2014) Detecting and correcting for family size differences in the study of sexual orientation and fraternal birth order. Archives of Sexual Behavior 43, 845-852.

Blanchard, R. \& Bogaert, A. F. (1996) Biodemographic comparisons of homosexual and heterosexual men in the Kinsey interview data. Archives of Sexual Behavior 25, 551-579.

Blanchard, R. \& Ellis, L. (2001) Birth weight, sexual orientation and the sex of preceding siblings. Journal of Biosocial Science 33, 451-467.

Blanchard, R. \& Lippa, R. A. (2007) Birth order, sibling sex ratio, handedness, and sexual orientation of male and female participants in a BBC Internet research project. Archives of Sexual Behavior 36, 163-176.

Blanchard, R. \& Sheridan, P. M. (1992) Sibship size, sibling sex ratio, birth order, and parental age in homosexual and nonhomosexual gender dysphorics. Journal of Nervous and Mental Disease 180, 40-47.

Blanchard, R. \& VanderLaan, D. P. (2015) Commentary on Kishida and Rahman (2015), including a meta-analysis of relevant studies on fraternal birth order and sexual orientation in men. Archives of Sexual Behavior 44, 1503-1509.

Blanchard, R., Zucker, K. J., Cavacas, A., Allin, S., Bradley, S. J. \& Schachter, D. C. (2002) Fraternal birth order and birth weight in probably prehomosexual feminine boys. Hormones and Behavior 41, 321-327. 
Blanchard, R., Zucker, K. J., Cohen-Kettenis, P. T., Gooren, L. J. \& Bailey, J. M. (1996) Birth order and sibling sex ratio in two samples of Dutch gender-dysphoric homosexual males. Archives of Sexual Behavior 25, 495-514.

Blanchard, R., Zucker, K. J., Siegelman, M., Dickey, R. \& Klassen, P. (1998) The relation of birth order to sexual orientation in men and women. Journal of Biosocial Science 30, 511-519.

Blanco, P., Sargent, C. A., Boucher, C. A., Mitchell, M. \& Affara, N. A. (2000) Conservation of PCDHX in mammals; expression of human X/Y genes predominantly in brain. Mammalian Genome 11, 906-914.

Bogaert, A. F. (2003) Interaction of older brothers and sex-typing in the prediction of sexual orientation in men. Archives of Sexual Behavior 32, 129-134.

Bogaert, A. F. (2006) Biological versus nonbiological older brothers and men's sexual orientation. Proceedings of the National Academy of Sciences of the USA 103, 10771-10774.

Bogaert, A. F. \& Skorska, M. (2011) Sexual orientation, fraternal birth order, and the maternal immune hypothesis: a review. Frontiers in Neuroendocrinology 32, 247-254.

Bozkurt, A., Bozkurt, O. H. \& Sonmez, I. (2015) Birth order and sibling sex ratio in a population with high fertility: are Turkish male-to-female transsexuals different? Archives of Sexual Behavior 44, 1331-1337.

Camperio Ciani, A., Corna, F. \& Capiluppi, C. (2004) Evidence for maternally inherited factors favoring male homosexuality and promoting female fecundity. Proceedings of the Royal Society of London, Series B: Biological Sciences 271, 2217-2221.

Cantor, J. M., Blanchard, R., Paterson, A. D. \& Bogaert, A. F. (2002) How many gay men owe their sexual orientation to fraternal birth order? Archives of Sexual Behavior 31, 63-71.

Christiansen, O. B., Kolte, A. M., Dahl, M., Larsen, E. C., Steffensen, R., Nielsen, H. S. \& Hviid, T. V. (2012) Maternal homozygocity for a 14 base pair insertion in exon 8 of the HLA-G gene and carriage of HLA class II alleles restricting HY immunity predispose to unexplained secondary recurrent miscarriage and low birth weight in children born to these patients. Human Immunology 73, 699-705.

Currin, J. M., Gibson, L. \& Hubach, R. D. (2015) Multidimensional assessment of sexual orientation and the fraternal birth order effect. Psychology of Sexual Orientation and Gender Diversity 2, 113-122.

Dierselhuis, M. P., Jankowska-Gan, E., Blokland, E., Pool, J., Burlingham, W. J., van Halteren, A. G. S. \& Goulmy, E. (2014) HY immune tolerance is common in women without male offspring. PLoS One 9, e91274.

Frisch, M. \& Hviid, A. (2006) Childhood family correlates of heterosexual and homosexual marriages: a national cohort study of two million Danes. Archives of Sexual Behavior 35, 533-547.

Gammil, H. S., Guthrie, K. A., Ayedelotte, T. M., Adams Waldorf, K. M. \& Nelson, J. L. (2010) Effect of parity on fetal and maternal microchimerism: interaction of grafts within a host? Blood 116, 2706-2712.

Gómez-Gil, E., Esteva, I., Carrasco, R., Cruz Almaraz, M., Pasaro, E., Salamero, M. \& Guillamon, A. (2011) Birth order and ratio of brothers to sisters in Spanish transsexuals. Archives of Sexual Behavior 40, 505-510.

Green, R. (2000) Birth order and ratio of brothers to sisters in transsexuals. Psychological Medicine 30, 789-795.

Hiby, S. E., Regan, L., Lo, W., Farrell, L., Carrington, M. \& Moffett, A. (2008) Association of maternal killer-cell immunoglobulin-like receptors and parental HLA-C genotyoes with recurrent miscarriages. Human Reproduction 23, 972-976.

Jamain, S., Quach, H., Betancur, C., Rastam, M., Colineaux, C., Gillberg, I. C. et al. (2003) Mutations of the X-linked genes encoding neuroligins NLGN3 and NLGN4 are associated with autism. Nature Genetics 34, 27-29. 
Khan, D. A. \& Baltimore, D. (2010) Pregnancy induces a fetal antigen-specific maternal T regulatory response that contributes to tolerance. Proceedings of the National Academy of Sciences of the USA 107, 9299-9304.

King, M. D., Green, J., Osborn, D. P. J., Arkell, J., Hetherton, J. \& Pereira, E. (2005) Family size in white gay and heterosexual men. Archives of Sexual Behavior 34, 117-122.

Kishida, M. \& Rahman, Q. (2015) Fraternal birth order and extreme right-handedness as predictors of sexual orientation and gender nonconformity in men. Archives of Sexual Behavior 44, 1493-1501.

Lippa, R. A. (2005) Sexual orientation and personality. Annual Review of Sex Research 16, 119-153.

Lissauer, D., Piper, K., Goodyear, O., Kilby, M. D. \& Moss, P. A. H. (2012) Fetal-specific CD8+ cytotoxic $\mathrm{T}$ cell response develop during normal human pregnancy and exhibit broad functional capacity. Journal of Immunology 189, 1072-1080.

Lo, Y. M., Lo, E. S., Watson, N., Noakes, L., Sargent, I. L., Thilaganathan, B. \& Wainscoat, J. S. (1996) Two-way cell traffic between mother and fetus: biologic and clinical implications. Blood 88, 4390-4395.

Marttila, S., Nevalainen, T., Kananen, L., Jylhävä, J., Jylhä, M., Hervonen, A., Ilonen, J. \& Hurme, M. (2015) Number of sons contributes to ageing-associated inflammation. Scientific Reports 5, 8631 .

Nielsen, H. S., Steffensen, R., Varming, K., Van Hakteren, A. G. S., Spierings, E., Ryder, L. P. et al. (2009) Association between HY-restricting HLA class II alleles with pregnancy outcome in patients with recurrent miscarriage subsequent to a firstborn boy. Human Molecular Genetics 18, $1684-1691$.

O'Donoghue, K., Chan, J., de la Fuente, J., Kenna, N., Sandison, A., Anderson, J. R. et al. (2004) Microchimerism in female bone marrow and bone decades after fetal mesenchymal stem-cell trafficking in pregnancy. Lancet 364, 179-182.

Piper, K. P., McLarnon, A., Arrazi, J., Horlock, C., Ainsworth, J., Killby, M. D. et al. (2007) Functional HY-specific CD8 $+\mathrm{T}$ cells are found in a high proportion of women following pregnancy with a male fetus. Biology of Reproduction 76, 96-101.

Rahman, Q. (2005) The association between the fraternal birth order effect in male homosexuality and other markers of human sexual orientation. Biology Letters 1, 393-395.

Rieger, G., Linsenmeier, J. A., Gygax, L. \& Bailey, J. M. (2008) Sexual orientation and gender nonconformity: evidence from home videos. Developmental Psychology 44, 46-58.

Schagen, S. E. E., Delemarre-van de Waal, H. A., Blanchard, R. \& Cohen-Kettenis, P. T. (2012) Sibling sex ratio and birth order in early-onset gender dysphoric adolescents. Archives of Sexual Behavior 41, 541-549.

Schwartz, G., Kim, R. M., Kolundzija, A. B., Rieger, G. \& Sanders, A. R. (2010) Biodemographic and physical correlates of sexual orientation in men. Archives of Sexual Behavior 39, 93-109.

VanderLaan, D. P., Blanchard, R., Wood, H., Garzon, L. \& Zucker, K. J. (2015) Birth weight and two possible types of maternal effects on male sexual orientation: a clinical study of children and adolescents referred to a Gender Identity Service. Developmental Psychobiology 57, 25-34.

VanderLaan, D. P., Blanchard, R., Wood, H. \& Zucker, K. J. (2014) Birth order and sibling sex ratio of children and adolescents referred to a Gender Identity Service. PLoS One 9, e90257.

VanderLaan, D. P. \& Vasey, P. L. (2011) Male sexual orientation in Independent Samoa: evidence for fraternal birth order and maternal fecundity effects. Archives of Sexual Behavior 40, 495-503.

Wampold, C. H. (2013) Redesigning fraternal birth order studies from top to bottom [Letter to the Editor]. Archives of Sexual Behavior 42, 1387-1389.

Xu, Y. \& Zheng, Y. (2015) Fraternal birth order, handedness, and sexual orientation in a Chinese population. Journal of Sex Research. doi: 10.1080/00224499.2015.1104530. 